\title{
SYMPOSIUM
}

\section{Phase specific strategies for the prevention, control, and elimination of sexually transmitted diseases: background country profile, England and Wales}

\author{
A M Johnson, K A Fenton, C Mercer
}

Sex Transm Infect 2002; 78(Suppl I):i1 25-i 132

The development of non-invasive tests for evidence of current or past infection offers new prospects for carrying out population studies of sexually transmitted infection (STI) epidemiology, and for improved understanding of the behavioural and biological determinants of STI transmission. In turn this may guide screening, treatment, and behavioural interventions. The evidence base for many interventions is sparse and randomised trials of interventions are in their early days. Increasingly, linked behavioural and biological outcomes will be required to measure effectiveness. Integrated efforts are needed at a national level to achieve greater coordination between STD, HIV, and contraception services, school education, and broader public education and programmes.

See end of article for authors' affiliations

Correspondence to Professor Anne Johnson, Centre for Infectious Disease Epidemiology, Departments of Primary Care and Population Sciences and Department of Sexually Transmitted Diseases, Royal Free and University College Medical School, Mortimer Market Centre, off Capper Street London WCIE 6AU, UK; ajohnson@gum.ucl.ac.uk

Accepted 30 November 2001
T he incidence of sexually transmitted infections (STIs) in populations results from the interaction between behavioural patterns, biological properties of STIs and the effectiveness of control programmes for diagnosis and treatment. In this paper we provide an overview of the STI control strategies, patterns of sexual behaviour, and the epidemiology of STIs in England and Wales. Demographic data are drawn from Government sources. Data on specific populations at high risk are drawn from several ad hoc published and unpublished surveys. Data on sexual behaviour are largely drawn from the British national survey of sexual attitudes and lifestyles (NATSAL) carried out in 1990/91 in a probability sample of 18876 men and women aged 16-59 resident in Britain. $^{1-3}$ STI data are drawn from surveillance statistics from sexually transmitted dieases clinics, which date back to the early 20th century.

\section{COUNTRY PROFILE: ENGLAND AND WALES}

The resident population of England and Wales was estimated in 1997 as 52.2 million. The dominant ethnic group is composed of white, British born residents. Ethnic minorities make up 5.9\% of the population, nearly half from India, Pakistan, and Bangladesh. Eighteen per cent of people in Britain live in households with an income below $60 \%$ of the median. ${ }^{4}$ The proportion of young people continuing in full time educational training beyond the age of 16 years has increased in the last decade and there has been a similar increase in the number entering higher education.

In England and Wales, the age of consent for heterosexual sexual intercourse for women is $\mathbf{1 6}$. It is illegal for a man to have sex with a girl under 16, and heterosexual anal sex is illegal. Male homosexual sex was a criminal offence until 1967 , and the age of male homosexual consent is currently 18 years. The Abortion Law Reform Act of 1968 legalised medical termination of pregnancy and set the limits on the time and circumstances under which abortion could legally be performed.

\section{EXISTING INFRASTRUCTURE}

STI diagnostic and treatment services

A clinical service for STI treatment and control was first established following a Royal Commission on venereal diseases in $1916 .^{5}$ STI clinics were run by local (government) authorities until 1948, when they were handed over to management by NHS hospitals. STI treatment services have always been provided free of charge, "open access" to the public, and do not require referral from a general practitioner. Clinics operate as a network with sharing of information in strict confidence between clinics to promote treatment and in particular partner notification. Health advisers, based in genitourinary medicine (GUM) clinics, are responsible for partner notification in addition to HIV education, testing, and counselling. Partner notification is generally patient referral based, the preferred method being the use of contact slips. The effectiveness of the current system is, however, uncertain, as there is no national surveillance of partner notification outcomes. Private practitioners have a limited role in STI diagnosis and treatment, as have general practitioners (GPs).

\section{Screening for STls}

Syphilis screening is carried out in all GUM and antenatal clinics, and has probably been undertaken since the 1950s on the basis of "custom and practice" without any stated policy. ${ }^{6}$ Over recent years, there has been a small but significant incidence of syphilis in the United Kingdom, mainly

Abbreviations: CDSC, Communicable Disease Surveillance Centre; GUM, genitourinary medicine; HAART, Highly active antiretroviral therapy; NATSAL, British national survey of sexual attitudes and lifestyles 1990 
acquired in the former Soviet Union, ${ }^{7}$ and outbreaks in inner city areas. ${ }^{8}$ Consequently, the National Screening Committee and the NHS recommended continuing universal antenatal screening for syphilis. ${ }^{9}$ Routine antenatal screening for HIV and hepatitis B are also currently recommended ${ }^{6}$; however, there are at present no other population based screening programmes for STIs. In 1998, the chief medical officer's expert advisory group on Chlamydia trachomatis concluded that diagnostic testing should be offered to all symptomatic individuals and those at high risk (GUM attenders and women seeking pregnancy termination). ${ }^{10}$ The government's new sexual health and HIV strategy ${ }^{11}$ has confirmed its commitment to a phased introduction of chlamydia screening, and the results of several pilot studies currently under way will determine the appropriate models of implementation in primary and secondary health care settings. If implemented, it is likely that the GP's role in primary care screening and treatment of STIs will increase significantly.

\section{Surveillance for sexually transmitted infections}

Surveillance data for all STIs (including HIV infection) are collated by the Public Health Laboratory Service, Communicable Disease Surveillance Centre (CDSC). ${ }^{12}$ STI surveillance data are compiled from five main systems: KC60 returns; laboratory reporting; laboratory surveillance of gonococcal antimicrobial resistance; enhanced syphilis reporting; and surveillance of blood donations. All of these are described in greater detail elsewhere. ${ }^{13}$

KC60 returns are the mainstay of STI surveillance in England and Wales, in which all GUM clinics have a statutory obligation to complete a statistical return of attendances in the previous quarter. Data collected include GUM clinic, condition, sex, number of male cases homosexually acquired (selected conditions only), and age group (selected conditions only). The current system covers a wide range of conditions and provides robust trend data for many (but not all) STIs. However, only aggregated data are collected and there is little information on behavioural risk factors, or regarding STIs seen outside GUM clinics.

Other STI surveillance schemes are generally based on laboratory reporting mechanisms. In the universal laboratory reporting system, all microbiology laboratories in England and Wales are invited to report all diagnosed STIs to CDSC on a voluntary basis. Data on laboratory, age, sex, organism, specimen type(s) and date(s), identification method(s), and antimicrobial susceptibilities (gonorrhoea only) are routinely collected from laboratory reports. Laboratory reports of STIs provide information on the diagnosis of STIs in settings other than GUM clinics.

Laboratory reporting and surveillance of antibiotic resistant gonococci is also undertaken passively by the genitourinary infections reference laboratory (GUIRL) in Bristol, and actively as part of the gonococcal resistance to antimicrobials surveillance programme (GRASP)—a sentinel surveillance system involving a network of 22 GUM clinics in England and Wales.

Surveillance for syphilis infections is another laboratory surveillance system involving six public health laboratories that perform reference treponemal serology. Data on source of report, type of syphilis, the patient's personal, demographic, and geographical details, and type of antibiotic resistance are collected, which allow early detection of incident cases.

Finally, surveillance of infections in blood donations is also undertaken, in which all blood donations in England and Wales are tested for syphilis, hepatitis B (HBV), and hepatitis C (HCV). Data on age, ethnicity, sex, and route of infection (exposure) of positive donors are reported to the National Blood Authority/CDSC surveillance system.

\section{Surveillance activities: HIV surveillance}

There are various surveillance activities which provide information on the epidemiology of HIV/AIDS in England and Wales:

- AIDS case reporting. Voluntary, confidential clinician reports of cases of severe HIV related disease meeting a surveillance AIDS case definition are collated by CDSC.

- Clinician HIV reporting has been introduced since 1 January 2000, with an expanded disaggregate dataset including a range of new demographic, behavioural, and clinical outcome markers.

- A large scale programme of unlinked anonymous HIV antibody testing of sera residues from blood specimens and other biological specimens is in place; these are collected from samples submitted for routine laboratory tests. Sentinel groups include pregnant women (using sera from rubella screening), STD clinic attendees (using sera from syphilis screening), newborn babies (from Guthrie cards), and injecting drug users in treatment (from saliva assays). This method achieves close to $100 \%$ coverage of the patient population and provides relatively unbiased estimates of prevalence over time. ${ }^{14-16}$

- Annual surveys of prevalent HIV infections diagnosed (SOPHID) from all sites managing and reporting HIV cases. Data items collected include health authority and local authority of patient residence, CD4 count at last visit, current treatment, and last known viral load estimate. With unlinked anonymous prevalence data, the survey is used to estimate the proportions of all infections that are undiagnosed. The SOPHID system monitors the prevalence of diagnosed HIV infections, clinical status, and resources used for managing HIV patients, and as such the data have been extremely useful to health service planning.

- A system of CD4 cell count surveillance has been established by reporting of CD4 cell count results from 80 laboratories. This system has been used to estimate the likely proportion of new infections (from those with high counts) and likely proportions of individuals eligible for treatment. ${ }^{17}$ CD4 monitoring has also enabled prospective monitoring of trends in aggregate CD4 counts in England and Wales. Recent reports have highlighted significant increases in median CD4 among HIV infected individuals on antiretroviral treatment. ${ }^{.7}$

- A national system for monitoring of antiretroviral drug resistance is currently being developed. This will allow surveillance of emergence of resistance strains. In combination with the UK register of HIV seroconverters, ${ }^{18}$ the system will also allow surveillance of transmission of resistant strains among newly infected, untreated individuals.

\section{Behavioural studies and surveillance}

The largest detailed probability survey of the general population anywhere in the world (NATSAL) was carried out in Britain in 1990-1991 ${ }^{1}$ and has been repeated in 1999-2000 using computer assisted technology among 11161 individuals aged 16-44 years resident in Britain.* A random half of respondents have been asked to provide urine samples for testing for $C$ trachomatis by ligase chain reaction. Results from this survey are expected in Autumn 2001. Behavioural surveillance has been established in a number of high risk populations, although data are patchy. Surveillance of syringe and needle sharing patterns among injecting drug users attending needle exchange programmes in London was one of the first to be established. $^{14}{ }^{19}$ Behavioural surveillance in gay men now

\footnotetext{
*Please see author's note.
} 


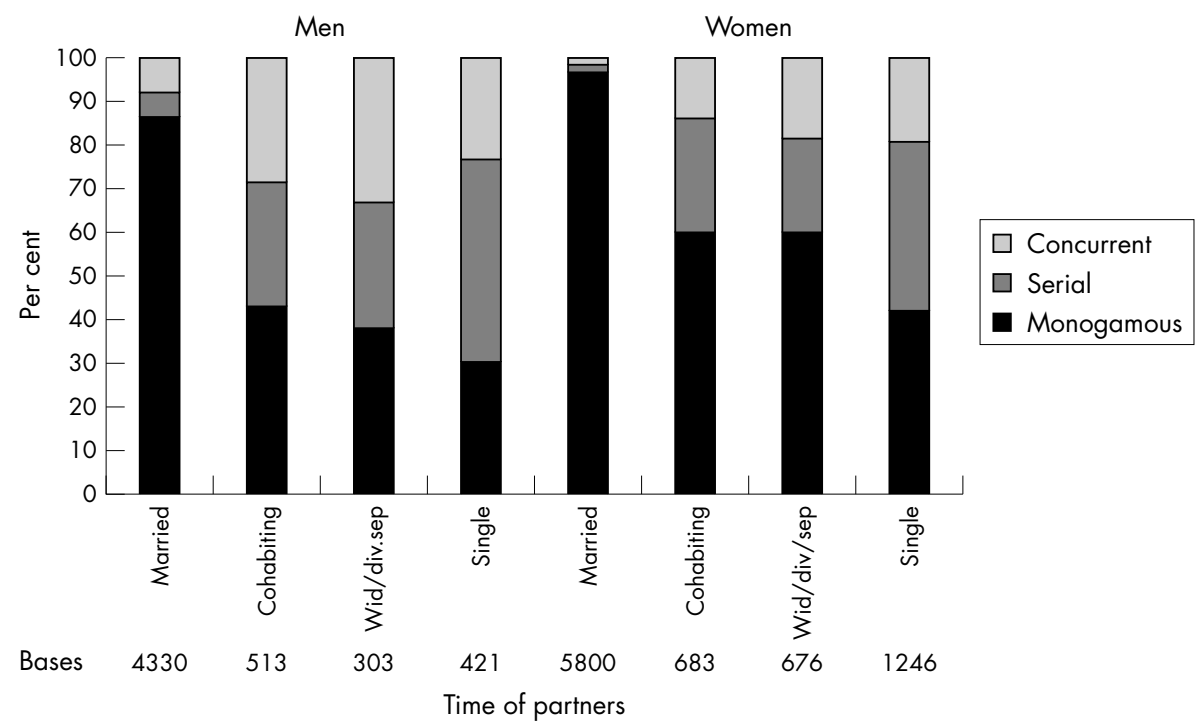

Figure 1 Marital status by timing of partners in the previous five years lexcludes all those with no sexual partner in the pasr five years).

includes serial surveys in gay bars, GUM clinics, and Gay Pride events in inner London ${ }^{20} 21$ and throughout Britain.

\section{NATURE OF SEXUAL NETWORKS}

\section{Sexual lifestyles of the general population}

Data from NATSAL show the very marked variability in patterns of partnership formation between individuals at a point in time and over the life course. ${ }^{22}$ At all ages, monogamous or serial patterns of partnership formation over a five year period are dominant, and monogamy increases greatly with age. Multiple partnerships within the last five years were reported by $60 \%$ of sexually active 16 to 24 year old men and by nearly half the women ( $95 \%$ by 45 to 59 years), and nearly $90 \%$ of men reported monogamy. Over the last year, $76.5 \%$ of women and $65.2 \%$ of men reported either no, or only one, heterosexual partner. A small proportion of individuals report very large numbers of partners and are likely to contribute disproportionately to the transmission of STIs in the population. For example, in the last five years, 12\% of partnerships reported by women and $16 \%$ reported by men were accounted for by the $1 \%$ of respondents with the greatest number of partners. Those in the youngest age group, 16 to 24 , are those consistently reporting the greatest number of partners in recent time periods (one to five years). In multivariate analyses, increased odds of multiple partnerships in the last year were associated with younger age, nonmarried status, higher social class, and first sexual intercourse before the age of $16 .^{22}$ Most of these factors are, in turn, associated with a greater risk of STI acquisition and STD clinic attendance.

\section{Concurrency}

Of those sexually active, $15.1 \%$ of men and $7.6 \%$ of women reported concurrent partnerships over the last five years. While the frequency of multiple partnership decreases rapidly with age, concurrent partnerships become the dominant pattern among those over 35 with multiple partnerships. Patterns of concurrency are also closely related to current relationship status (fig 1). Those who were married had very high rates of monogamy in the last five years. Those cohabiting at the time of the survey had similar patterns to those who were single, widowed, separated, or divorced, suggesting that although the effect may be confounded by age, cohabitation may not exert such a strong influence on monogamy as marriage.

\section{Sexuality}

In the sample, $6.1 \%$ of men and $3.4 \%$ of women reported any kind of same sex experience, and $3.5 \%$ and $1.7 \%$, respectively, reported ever having had a homosexual partner in their life; $1.4 \%$ of men and $0.6 \%$ of women reported a same sex partner in the last five years. The majority of those with a homosexual experience also had heterosexual experience. As with heterosexual partnerships there was great variation between individuals in the numbers of partners reported. Large

Table 1 Comparison of behaviours of STD clinic attenders in last five years with those of non-attenders

\begin{tabular}{|c|c|c|c|c|}
\hline & \multicolumn{2}{|l|}{ Men } & \multicolumn{2}{|l|}{ Women } \\
\hline & $\begin{array}{l}\text { STD clinic } \\
\text { attenders }\end{array}$ & Non-attenders & $\begin{array}{l}\text { STD clinic } \\
\text { attenders }\end{array}$ & Non-attenders \\
\hline \multicolumn{5}{|c|}{ Number of heterosexual and homosexual partners } \\
\hline Last year & $2.75(0.22)$ & $1.29(0.074)$ & $1.37(0.06)$ & $1.00(0.007)$ \\
\hline Ever & $23.03(2.05)$ & $11.09(1.20)$ & $9.01(0.56)$ & $3.46(0.14)$ \\
\hline Base $N^{*}$ : & 262 & 7370 & 250 & 9334 \\
\hline Concurrent partners in last five years & $41.7 \%$ & $11.4 \%$ & $21.7 \%$ & $6.0 \%$ \\
\hline Base $\mathrm{N \dagger}$ : & 223 & 6370 & 217 & 8147 \\
\hline \multicolumn{5}{|l|}{ Condom use } \\
\hline All occasions in last four weeks & $21.9 \%$ & $16.7 \%$ & $18 \%$ & $13.8 \%$ \\
\hline Base $N \ddagger:$ & 215 & 5529 & 189 & 6919 \\
\hline
\end{tabular}

Values are mean (SEM) or per cent. Source: NATSAL 1990/1 1

*All respondents who had ever had sexual intercourse; tall respondents with partners in last five years; fall respondents who had sex in last four weeks. 
numbers (more than 20) of female homosexual partnerships were not observed, but among men with homosexual partnerships, $11.4 \%$ reported 20 or more lifetime partners.

\section{STD clinic attenders}

STD clinic attendance rates in the last five years are highest in those aged 16 to 34 . Overall, $3.4 \%$ of men and $2.6 \%$ of women reported attending an STD clinic in the last five years. The probability of attending an STD clinic increases rapidly with increasing numbers of partners: $13.7 \%$ of men with five or more heterosexual partners and 15\% of women with five or more heterosexual partners in the last five years had attended a clinic. Among men with homosexual partners, over half with five or more partners in the last five years had attended a clinic. ${ }^{22}$ In comparing the behaviours of those attending STD clinics with those who had not (table 1), the former report a much higher mean number of partners in the last year and lifetime, and higher rates of concurrency.

\section{Commercial sex workers}

The number of women working in the sex industry is unknown, though several different methods including capture-recapture have been used in local surveys of prostitutes in cities. Across Europe, estimates of the number of women working in the sex industry are in the range of 1 in 600 to $\mathrm{l}$ in 3000 (Ward $\mathrm{H}$, personal communication). Estimates for London are in the range of 4-5000 for a population of seven million ( 1 in 1400 to $l$ in 1750 ) (Ward H, personal communication). Commercial sex takes place various settings including street soliciting and bars, as well as more discrete methods (for example, saunas, escort agencies, and more recently through the internet). While commercial sex per se is not illegal in England and Wales, many of the activities associated with prostitution, including soliciting, pimping, and running brothels, are illegal. There is a high incidence of injecting drug use in sex workers, and this is thought to be higher in street workers than indoor workers. ${ }^{23}$ HIV prevalence in female sex workers in Britain is low, and is generally associated with injecting drug use or sex with an infected non-commercial partner. ${ }^{24}$ Studies of commercial sex workers have generally found extremely high condom use with clients but limited use with non-paying partners. ${ }^{24}$ In major cities there is also anecdotal evidence of male commercial sex work, but the magnitude is unknown. ${ }^{25}$

\section{Clients of commercial sex workers}

Few studies have focused specifically on clients of sex workers. Day et al, ${ }^{26}$ in a study of clients attending a London STD clinic, found that few were HIV infected and that condom use was reportedly high (82\%). NATSAL 1990/1 indicated that $6.8 \%$ of men reported paying for sex with a woman at some time in their lives. ${ }^{1}$ Contact with commercial sex workers is strongly associated with increasing numbers of partners: $17 \%$ of those with 10 or more partners in their lifetime reported a history of commercial sex contact. In a multivariate analysis of data from NATSAL, raised odds of ever paying for sex were associated with increasing age; previous marriage or current cohabitation (outside marriage); a history of working away from home; and a history of having a homosexual partner.

\section{SOCIAL AND BEHAVIOURAL INTERVENTIONS \\ Sexual health promotion}

The early part of the previous century saw STI prevention campaigns focused particularly on troops in wartime, using a combination of prescriptive health education messages and chemical prophylaxis. ${ }^{27}$ In the 1960s, liberalising legislative reform in relation to homosexuality, abortion, and divorce was introduced. In 1988, the Education Reform Act introduced substantial changes in education, in particular the establishment of a national curriculum, with school based sex education-dealing with the biological aspects of sexbecoming compulsory.

With the emergence of AIDS in the mid-1980s, efforts to promote sexual heath intensified. HIV/AIDS prevention had a very high priority at Department of Health and government level, and between 1986 and 1993 a series of high profile public education campaigns using press, posters, television, radio, and a house by house leaflet drop were carried out. This aimed at increasing public awareness about AIDS, normalising condom usage, and highlighting the risks associated with travel. A government HIV/AIDS health promotion strategy, introduced in 1996, recognised the need to deliver general education campaigns while simultaneously supporting proactive interventions with "vulnerable" groups, for example gay and bisexual men. Needle exchange schemes were introduced in the mid to late 1980s, and HIV prevalence in intravenous drug users has been maintained at low levels. Initial efforts of the gay community, with a well organised voluntary sector, spearheaded intense community education campaigns. Investment in the GUM services was substantial. There is good evidence that these interventions achieved a rapid change in behaviour, a decreased incidence of STIs, and a decline in HIV incidence. ${ }^{27}$ In the late 1990 s greater attention was focused on the problems of young people, as demonstrated by high teenage pregnancy rates and increased rates of STI. In 1999 the Government announced its intention to develop a sexual health strategy for England which was published in 2001. ${ }^{11}$

\section{DESCRIPTIVE EPIDEMIOLOGY AND TIME TRENDS}

England and Wales are among a few countries that have a robust recording system for STIs, and these diseases have been reported since 1917. Over time, observation of trends has improved our understanding of disease epidemiology and the impact of various social and medical interventions, including war, effective antibiotic treatment, and the liberalisation of sexual attitudes and lifestyles.

\section{Bacterial and viral STDs}

The reported number of gonococcal infections has changed dramatically over time (fig 2), with peak reports being observed in periods following both world wars and more recently, during the late 70 s and early 80 s. The decline after the second world war may be attributable to changes in behaviour among men and the introduction of penicillin. Dramatic rises in the 1970s and 1980s are likely to be influenced both by behaviour changes (see below) and by changes in delivery of service. There was expansion of GUM services in the 1960s, and the introduction of the Thayer-Martin medium for gonorrhoea diagnosis. While behaviour change may have contributed to a real increase in transmission of gonorrhoea, the 1970s rise may in part have been due to increased ascertainment (as with chlamydia currently), and the subsequent decline to improved overall control. Perhaps the most striking change, however, was the dramatic reductions in the numbers and rates of infections observed during the mid to late eighties, associated with behavioural modifications in response to the HIV/AIDS pandemic. Reported numbers and rates of gonorrhoea were at their lowest between 1993 and 1995; however, since then the rates have increased, with a $31 \%$ rise in the number of uncomplicated gonorrhoea diagnoses (9637 to 12670 ) between 1994 and 1997. Increases have been significant among young heterosexual people and among older gay and bisexual men (over 35 years). ${ }^{28}$

Proactive surveillance and reporting of genital chlamydial infection began in the mid-1980s. The numbers and rates of diagnoses have gradually increased over time, reflecting technological developments and increasing testing and screening within GUM clinics. Chlamydia rates are highest among young women aged 16 to 19 years and men aged 19 to 25 . Between 1998 and 1999, diagnoses rose by 16\% (fig 3). 

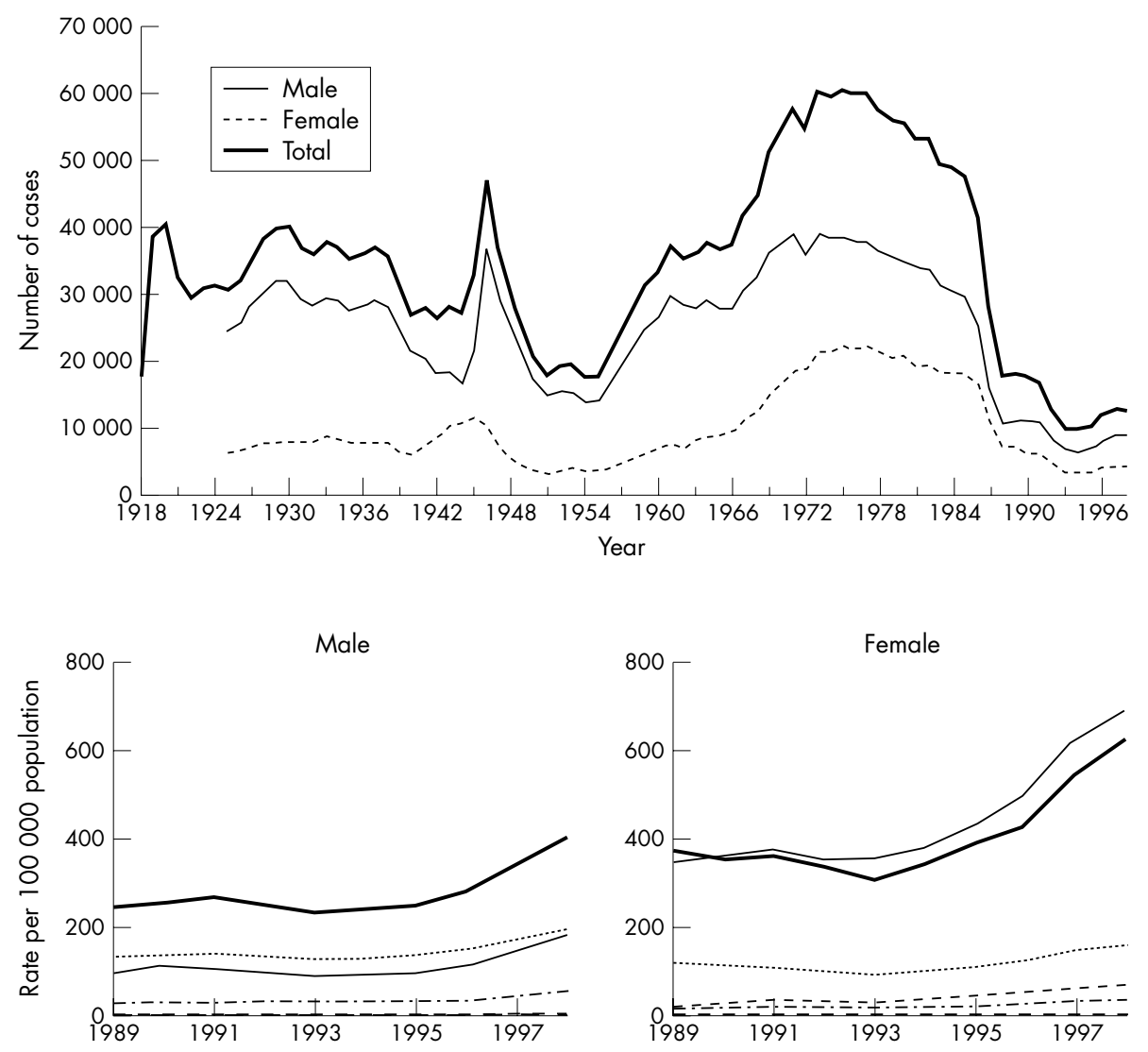

Figure 3 Rates of uncomplicated genital chlamydia infection seen in genitourinary medicine clinics by age group, England and Wales, 1989 to 1998.
Figure 2 Cases of gonorrhoea seen in genitourinary medicine clinics England and Wales, 1918 to 1998 .

\begin{tabular}{|c|c|c|}
\hline \multicolumn{3}{|c|}{ Age group (years) } \\
\hline$---<16$ & $-20-24$ & $\cdot \cdot--35-44$ \\
\hline$-16-19$ & $25-34$ & $---45+$ \\
\hline
\end{tabular}

Diagnoses of infectious syphilis at genitourinary medicine (GUM) clinics in England and Wales peaked towards the end of the second world war (fig 4). Diagnoses in males increased moderately through the 1960s and 1970s, while numbers of female cases remained constant, but subsequently declined in the early to mid-1980s, coinciding with emerging awareness of HIV, adoption of safer sex practices, and a parallel fall in HIV transmission among male homosexuals. The incidence of infectious syphilis in England and Wales is low compared with other STIs. However, recent increases in syphilis reports have been observed, associated with infections acquired outside the United Kingdom (particularly in Eastern Europe) and with "disease outbreaks" in population subgroups. A sharp rise in the number of heterosexually acquired syphilis diagnoses in the Bristol area in 1997 (which subsided in 1998), and by June 2000 outbreaks of syphilis among gay and bisexual men (many of whom were HIV positive) had been described in Manchester, Brighton, and London..$^{29} 30$

Genital warts are the most common STI diagnosed at GUM clinics in England and Wales. First episode, recurrent, and reregistered cases accounted for 22\% (116 134 of 524203 ) of all diagnoses made in GUM clinics in 1998. Between 1971 and 1998, the number of diagnoses of all genital warts (first episode, recurrent, and reregistered cases) increased by more than 7- and 11 -fold in men and women, respectively. Genital herpes simplex virus (HSV) infection is the most common ulcerative STI in England and Wales. Between 1971 and 1998, the number of genital HSV diagnoses made at GUM clinics increased by 4- and 18-fold in men and women, respectively. Between 1989 and 1998, diagnoses of first episode genital HSV in females rose from 25 to 37 per 100000 population. Diagno- sis rates are highest in 20 to 24 year old men and women, and in London.

\section{A phase specific approach to STI surveillance and control?}

Overall, common infections such as warts and chlamydia remain widely distributed throughout the population. Genital warts may be described as being in phase 2 (hyperendemic control phase), although - as for genital herpes - the continued increases observed over the past two decades may reflect underlying behavioural change as well as improved diagnosis and ascertainment. For chlamydia, current prevention interventions are still largely geared towards determining population prevalence, ${ }^{31}$ asymptomatic screening, awareness raising, and the provision of rapid and sensitive diagnostic tests within and outside of GUM settings. A greater understanding of the hyperendemic levels of infection, particularly among women attending for termination of pregnancy, prompted calls for the introduction of targeted screening programmes. ${ }^{11}$

In contrast, curable conditions such as syphilis and gonorrhoea have been subject to more than 50 years of a coordinated control programme and are now largely limited to core groups. Syphilis was, until the late 1990s, being driven towards very low endemic levels in England and Wales (phase 4). By 1994, rates of syphilis had fallen to their lowest levels since reporting began, and incident infections were largely imported from high prevalence countries. Recent outbreaks of syphilis have highlighted the vulnerability of existing sexual networks (particularly HIV positive homosexual men) to explosive outbreaks of infection once reintroduced. ${ }^{32}$ The recent outbreaks of syphilis have led to renewed syphilis education programmes 


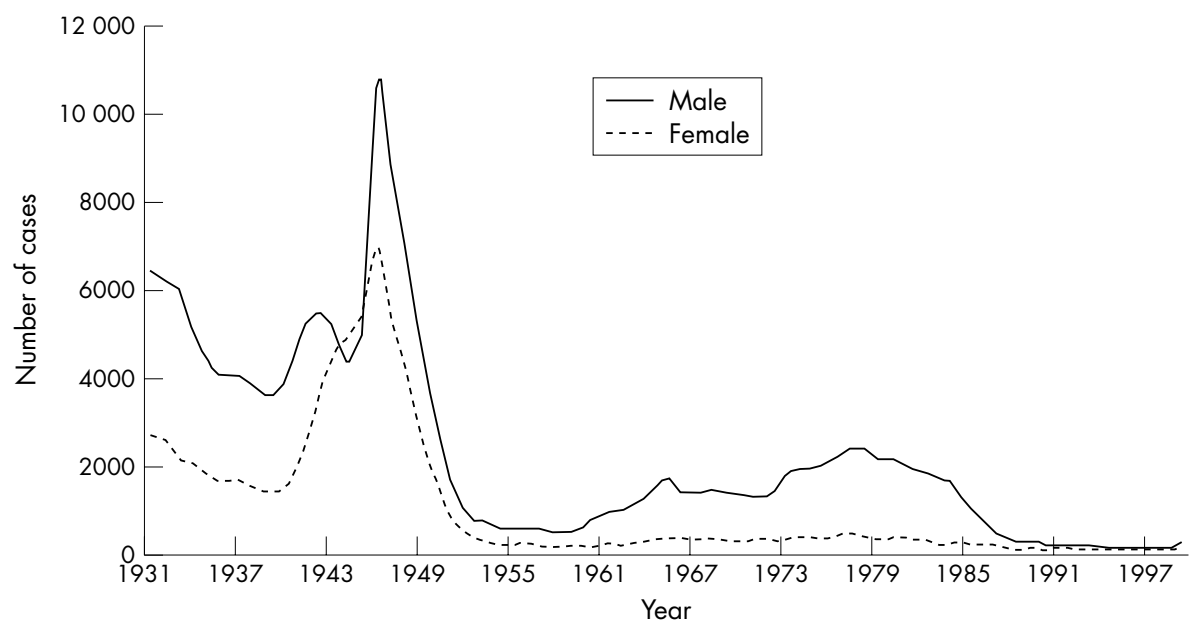

Figure 4 Cases of syphilis (infectious and latent in the first two years of infection) seen in genitourinary clinics England and Wales, 1931 to 1999.

Table 2 New diagnoses of selected conditions made in genitourinary medicine clinics in England, by sex, 1999

\begin{tabular}{llllll}
\hline & $\begin{array}{l}\text { Syphilis } \\
\text { (primary and } \\
\text { secondary) }\end{array}$ & $\begin{array}{l}\text { Gonorrhoea } \\
\text { (uncomplicated) }\end{array}$ & $\begin{array}{l}\text { Genital herpes } \\
\text { (first attack) }\end{array}$ & $\begin{array}{l}\text { Genital warts } \\
\text { (first attack) }\end{array}$ & $\begin{array}{l}\text { Genital chlamydia } \\
\text { (uncomplicated) }\end{array}$ \\
\hline $\begin{array}{l}\text { Male } \\
\text { Male }\end{array}$ & 152 & 10651 & 6052 & 32075 & 21800 \\
(homosexually & & & & & \\
acquired), $\mathrm{n}(\%)$ & $51(33 \%)$ & $1831(17.2 \%)$ & $335(5.5 \%)$ & $1585(5 \%)$ & $612(2.8 \%)$ \\
$\begin{array}{l}\text { Female } \\
\text { Total }\end{array}$ & 54 & 4921 & 9811 & 29484 & 29283 \\
\hline
\end{tabular}

targeting those at greatest risk and those health care workers likely to treat them. Enhanced surveillance programmes have been introduced to collect more detailed information on incident cases, and information on social and sexual networks has been used to inform targeted prevention interventions.

For gonorrhoea, overall declining rates of diagnosed infections in the early 1990s were accompanied by a concomitant disease concentration among homosexual men, young people in deprived urban areas, and some ethnic minority groups-consistent with a phase 4 picture. ${ }^{28}$ However, the resurgence of disease rates since the mid-1990s may indicate movement towards hyperendemic levels last seen in the pre-AIDS era (fig 2). In this instance, general and targeted population sexual health promotion approaches have been employed to raise awareness about this infection. The new GRASP surveillance initiative was introduced to assess the contribution of gonococcal resistance to disease transmission. Various ad hoc research studies have supplemented STI surveillance data and identified hyperendemic foci of infection which now require dedicated and sustained targeting. Table 2 shows the disproportionate burden of gonorrhoea and syphilis in gay men.

\section{HIV/AIDS trends}

By the end of 1998 there were an estimated 16000 men infected with HIV through sex between men, living in the United Kingdom. ${ }^{33}$ Annually, more than 1400 new diagnoses of HIV infection acquired through sex between men in the United Kingdom have occurred since 1990. Although it was initially predicted that the number of new AIDS cases would decline in the late 1990s, it has in fact been accelerated by the introduction of highly active retroviral therapy (HAART). The majority of diagnoses of HIV/AIDS among men infected through sex with other men have occurred in the London region. In 1998 the unlinked anonymous survey of GUM clinic attenders showed a high prevalence of HIV in men who have sex with men: $8.4 \%$ in London, $2.0 \%$ in Scotland, and $2.7 \%$ in the rest of the United Kingdom. ${ }^{33}$ Around 28\% of HIV infected homosexual and bisexual men remain undiagnosed.

Among heterosexuals, a somewhat different picture is observed. An estimated 11000 adults who had acquired their infection through heterosexual sex were living with HIV in the United Kingdom in 1998, accounting for nearly 30\% of the current HIV related case load. Around half of these were probably unaware of their infection. ${ }^{33}$ The number of new diagnoses of HIV infection attributed to heterosexual exposure reported rose from around 100 in 1986 to over 1000 in 1999. Most heterosexual HIV infections are thought to have been acquired in high prevalence countries abroad, mainly Africa. In 1998, HIV prevalence among heterosexual attenders at GUM clinics (a group at increased risk of infection) varied according to locality. In London, it was about $0.77 \%$ among men and 0.60\% among women; in the rest of England and Wales prevalence was about $0.12 \%$ (men) and $0.09 \%$ (women), and in Scotland it was $0.17 \%$ (men) and $0.30 \%$ (women)..$^{33}$ There have been reports of over 1600 children born to HIV infected mothers. ${ }^{34}$ Maternal HIV infection was usually acquired abroad, predominantly in east and central Africa. In contrast, in Scotland almost all reported cases are associated with injecting drug use by the mother or her partner. ${ }^{35}$ In 1998 , despite initiatives to increase the uptake of voluntary confidential HIV testing during antenatal care, about $60 \%$ of HIV infected pregnant women having babies in the United Kingdom remain undiagnosed at the time of giving birth.

Best estimates suggest that around 1600 injecting drug users were living with HIV by the end of 1998, most of whom were diagnosed. ${ }^{33}$ Since 1988, the number of new HIV diagnoses attributed to injecting drug use has remained about 
150 a year in England, Wales, and Northern Ireland. The median age at HIV diagnosis has risen with time, which suggests that many of the more recent diagnoses are in individuals from an ageing cohort mainly infected some time ago. ${ }^{36}$ In over 1300 cases, HIV infections are attributed to treatment for coagulation disorders (usually haemophilia A or B) in the United Kingdom, and of these about 500 are currently living with HIV infection. ${ }^{37}$ Many of those infected are young; 39\% were diagnosed when under 20, compared with $1 \%$ for the other risk categories combined. The progression of HIV related disease, which has been shown to be age related, has often been slow. ${ }^{37}$ There have been no reports of transmission of HIV through clotting factor treatment for haemophilia in the United Kingdom since the implementation of heat treatment blood products in the mid 1980s.

\section{Trends in sexual behaviour}

There is evidence of substantial change in sexual behaviour over the last 40 years. The median age at first intercourse has fallen from 20 for women ( 19 for men) born in 1931-45 to 17 for women and men born between 1966 and 1974. The proportion having sex before 16 has similarly risen substantially. ${ }^{1}$ There is evidence from retrospective data of increasing rates of partner change. The proportion of men and women reporting 10 or more heterosexual partners in their lifetime has steadily increased over the last 40 years, the proportionate increase being more marked for women. For women having their first intercourse in the 1950s, fewer than $5 \%$ reported 10 lifetime partners by the time of the survey in 1990. In contrast, more than $10 \%$ of women having first intercourse between 1975 and 1980 reported 10 or more heterosexual partners. These changing patterns of sexual behaviour are likely to have contributed to the epidemic of gonorrhoea in the 1970s. Since the early to mid-1980s condoms have been promoted for HIV and STD risk reduction. The proportion of men and women using condoms at first intercourse remained remarkably stable in the 1960s and 70s but rose markedly from the mid-1980s onwards.

There is some evidence that contact with commercial sex workers has declined over the century, and this may reflect the considerable change in women's sexual behaviour. It has become acceptable for women to have sexual partners before marriage and to have multiple partners over their life course. Data on first intercourse from NATSAL 1 indicate that $3.4 \%$ of men born in 1931-45 reported first sex with a prostitute, declining to $0 \%$ among men born in $1966-74 ; 38.5 \%$ of women and $14.2 \%$ of men born in 1931-45 had their first intercourse within marriage, declining to $0 \%$ of women and $0.8 \%$ of men born in 1966-74.

There are clear age related associations with homosexual experience. In NATSAL, those aged 45-59 are most likely to have ever had a homosexual experience. This may partly reflect legalisation of homosexuality in 1967, when this cohort were between 12 and 21 years of age. Prevalence of homosexuality varies substantially by region, with higher prevalence in London (46\% of men with homosexual partners in the last five years in NATSAL 1 lived in Greater London). ${ }^{38}$ The higher level of homosexual activity in London is reflected in the raised rates of STIs and HIV in London compared with elsewhere. This reflects the migration of men into London for the greater availability of gay venues and more tolerant attitudes. Behavioural surveillance shows that in London, risk behaviour among gay men has increased for the last three years, with a year on year increase in unprotected anal intercourse. ${ }^{20}$

\section{DISCUSSION}

England and Wales, in comparison with many other countries, has unusually comprehensive data on STDs and sexual behaviour. This is a direct consequence of having long established open access STI treatment and care services, combined with active disease surveillance systems. This, combined with a comprehensive HIV surveillance system and a large population based sexual behaviour survey, gives significant intelligence on sexual health. In comparison with the USA and some other countries in Europe, there are relatively low levels of STIs, HIV, and AIDS. ${ }^{39} 40$

The phase specific strategy concept provides a useful framework for interpreting and understanding STI epidemics, especially when applied to localised outbreaks of bacterial STIs (for example, ciprofloxacin resistant gonorrhoea or infectious syphilis). Indeed, we have recently been able to observe and document the resurgence of syphilis among homosexual men, and its subsequent movement through all four phases. ${ }^{32}$ However, we would argue that the phase specific concept is somewhat less well suited to understanding national trends in STI transmission. This in part reflects the observation that overall disease trends comprise many smaller more localised epidemics at different phases of evolution. At a national level, the concept is perhaps better suited for understanding STIs in the elimination phase (phase 4), for example syphilis, where low level endemicity and progress towards elimination are characteristic. Once again, our recent experiences with syphilis in England have highlighted the importance of understanding the evolution of sexual networks, and the need for targeted community based interventions with those at greatest risk. At the national level, phase 1 stage epidemics are hardly ever observed, except with the introduction of a new pathogen. However, rapid increases to hyperendemic levels may well be occurring for gonorrhoea-despite the existence of established STI control programmes. We are as yet uncertain whether, and at what level, the observed increases will begin stabilising. Thus in this instance the phase 2 hyperendemic levels may be relative rather than absolute. This illustrates another potential weakness of the phase specific concept when applied nationally. It is best applied with hindsight, and it may be difficult to determine the current phase. Finally, although improvements in STI diagnosis and treatment may have contributed to the observed declines in STI rates in the late 1980s (phase 3), the trends undoubtedly reflect behavioural modification adopted in response to the emerging HIV pandemic. ${ }^{41}$ The phase specific concept must acknowledge the dominance of sexual behaviour (and its determinants) on STI incidence.

But despite this, significant challenges remain. STI rates and teenage pregnancy rates have recently shown an upward turn, and recent reports of STI outbreaks highlight concerns about a relapse to unsafe sexual behaviours. Recently, greater attention has been paid to the sexual health needs of the ethnic minority population. Ad hoc surveys have shown increased gonorrhoea incidence in Afro-Caribbean populations, ${ }^{42-44}$ and substantially increased HIV prevalence in African populations. HAART, while prolonging life, has resulted in increased prevalence of HIV in the community and an increased force of infection. Evidence of increased risk behaviour and increased STI incidence in the most severely affected group of gay men suggests that behavioural interventions must be intensified in this group. This is of particular concern with evidence of emerging antiretroviral resistance and transmission of resistant viruses. Too little focus has been placed on the health promotion needs of HIV positive people, while maintaining STI control and the medical management of HIV. As in other areas of prevention, investment in interventions must be based on sound evidence of effectiveness.

However, there are opportunities. The development of noninvasive tests for evidence of current or past infection offers new prospects for carrying out population studies of STI epidemiology and for improving our understanding of the behavioural and biological determinants of STI transmission. This in turn may guide screening, treatment, and behavioural interventions. The evidence base for many interventions is 
sparse, and randomised trials of interventions are in their early days. Increasingly, linked behavioural and biological outcomes will be required to measure effectiveness. STI surveillance will need to move towards collecting person based data, enabling greater focus on core groups and a better understanding of the geographical variations. Finally, integration of efforts is needed at a national level to achieve greater coordination between STI, HIV, and contraception services, better school education, and broader public education and programmes. The recently published sexual health strategy sets much of the future policy agenda.

\section{AUTHOR NOTE}

Since the submission of this paper, the results of the second National Survey of Sexual Attitudes and Lifestyles (Natsal 2000) has been published. Johnson AM, Mercer CH, Erens B, et al. Sexual behaviour in Britain: Partnerships, practices, and HIV risk behaviours. Lancet 2001;358:1835-42. Fenton KA, Korovessis C, Johnson AM, et al. Sexual behaviour in Britain: reported sexually transmitted infections and prevalent genital Chlamydia trachomatis infection. Lancet 2001;358:1851-4. Wellings K, Nanchahal K, Macdowall W, et al. Sexual behaviour in Britain: early heterosexual experience. Lancet 2001;358:1843-50.

\section{Authors' affiliations}

A M Johnson, C Mercer, Centre for Infectious Disease Epidemiology, Department of Sexually Transmitted Diseases, Royal Free and University College London Medical School, London WC 1, UK

K A Fenton, HIV/STI Division, Public Health Laboratory Service,

Communicable Disease Surveillance Centre, London NW9, UK

\section{REFERENCES}

1 Johnson AM, Wadsworth J, Wellings K, et al. Sexual attitudes and lifestyles. Oxford: Blackwell Scientific Press, 1994.

2 Johnson AM, Wadsworth J, Wellings K, et al. Sexual lifestyles and HIV risk. Nature 1992;360:410-12.

3 Wellings K, Field J, Johnson AM, et al. Sexual behaviour in Britain. London: Penguin Books, 1994

4 Department of Social Security. Family resources survey 1996-1998. London: DSS, 1998

5 Adler MW. The terrible peril: a historical perspective on the venereal diseases. BMU 1980;281:206-11.

6 Newell M-L, Thorne C, Pembrey L, et al. Antenatal screening for hepatitis B and syphilis in the UK. Br J Obstet Gynaecol 1999; 106:66-71.

7 Ratcliffe L, Nicoll A, Carrington D, et al. Reference laboratory surveillance of syphilis in England and Wales 1994 to 1996. Communicable Disease and Public Health 1998;1:14-21.

8 Anon. Syphilis in Bristol 1997-8: an update. Commun Dis Rep 1998;8:413-16.

9 NHS Executive. Screening of pregnant women for syphilis (Health Service Circular). London: Department of Health (in press).

10 Chief Medical Officer's Medical Advisory Group. Main report of the CMO's Expert Advisory Group on Chlamydia trachomatis. London: Department of Health, 1998.

11 Department of Health. The national strategy for sexual health and HIV. London: $\mathrm{DOH}, 2001$

12 Lamagni T, Hughes $G$, Rogers $P$, et al. New cases seen at genitourinary medicine clinics: England 1998. Commun Dis Rep Suppl 1999;9:S1-12.

13 Anon. Surveillance of sexually transmitted infections in England and Wales. Eurosurveillance 1998;3:61-5.

14 Report from the Unlinked Anonymous HIV Surveys Steering Group (Chairman, Dr Eileen Rubery). Unlinked anonymous HIV prevalence monitoring programme in England and Wales: report from the Unlinked Anonymous HIV Surveys Steering Group: data to the end of 1993. London: Department of Health, 1995.

15 Report of an Expert Group (Chairman, Prof N E Day) convened by the Director of the Public Health Laboratory Service on behalf of the Chief Medical Officer. The incidence and prevalence of AIDS and prevalence of other severe HIV disease in England and Wales for 1995 to 1999: projections using data to the end of 1994. Commun Dis Rep $1996 ; 6: R 1-24$

16 Petruckevitch A, Nicoll A, Johnson A, et al. Direct estimates of prevalent HIV infection in England and Wales for 1991 and 1993. Genitourin Med 1997;73:345-54
17 Gupta SB, Gilbert RL, Brady AR, et al, on behalf of the CD4 Surveillance Scheme Advisory Group. CD4 cell counts in adults with newly diagnosed HIV infection: results of surveillance in England and Wales, 1990-1998. AIDS 2000; 14:853-61

18 Porter K, Johnson AM, Phillips AN, et al. The practical significance of potential biases in estimates of the AIDS incubation period distribution in the UK Register of HIV Seroconverters. AIDS 1999;13:1943-51.

19 Hart GJ, Carvell ALM, Woodward N, et al. Evaluation of needle exchange in central London: behaviour change and anti-HIV status over one year. AIDS 1989;3:261-5.

20 Dodds JP, Nardone A, Mercey DE, et al. Increase in high risk sexual behaviour among homosexual men, London 1996-8: cross sectional, questionnaire study. BM 2000;320:1510-11.

21 Weatherburn $\mathbf{P}$, Stephens $M$, Reid D, et al. Vital statistics. Findings from the National Gay Men's Sex Survey 1999. London: Sigma Research and CHAPS, 2000.

22 Scarlatti G, Hodara V, Rossi P, et al. Transmission of human immunodeficiency virus type 1 (HIV-1) from mother to child correlates with viral phenotype. Virology 1993;197:624-9.

23 Scambler G, Scambler A. Social change and health promotion among women sex workers in London. Health Promot Int 1995;10:17-24.

24 Ward H, Day S, Mezzone J. Prostitution and HIV risk: prostitute women in London. BM 1993;307:356-8.

25 Whittaker D, Hart G, Mercey D, et al. Satellite clinics and delivery of sexual health services to the "hard to reach": an evaluation. Final report to North Thames Regional Health Authority, March 1996:1-1 18.

26 Day S, Ward H, Perrotta L. Prostitution and risk of HIV: male partners of female prostitutes. BM 1993;307:359-61.

27 Wellings K, Field B. Stopping AIDS. London: Longman, 1996.

28 PHLS (England, Wales, and N Ireland DHSS; PS Northern Ireland and Scottish ISD, Collaborative Group). Trends in sexually transmitted infections in the United Kingdom 1990-1999. London: Public Health Laboratory Service, 2000.

29 Communicable Disease Surveillance Centre. Increased transmission of syphilis in Manchester. Commun Dis Rep Weekly 2000;10:89.

30 Communicable Disease Surveillance Centre. Increased transmission of syphilis in men who have sex with men reported from Brighton and Hove. Commun Dis Rep Weekly 2000;10:177.

31 Fenton KA, Copas A, Mitchell K, et al. The acceptability of urinary LCR testing for Chlamydia trachomatis among participants in a probability sample survey of sexual attitudes and lifestyles. Sex Transm Inf 2001;77:194-8.

32 Fenton KA, Nicoll A, Kinghorn G. Resurgence of syphilis in England: time for more radical and nationally coordinated approaches. Sex Transm Inf 2001;77:309-10.

33 Unlinked Anonymous Surveys Steering Group. Prevalence of HIV in the United Kingdom: Annual report of the unlinked anonymous prevalence monitoring programme. Data to the end of 1998. London: Department of Health, Public Health Laboratory Service, Institute of Child Health (London), and Scottish Centre for Infection and Environment, 1999.

34 Communicable Disease Surveillance Centre. AIDS and HIV infection in the United Kingdom: monthly report. Commun Dis Rep Weekly 2000; 10:37-40

35 Molesworth A, Tookey P. Paediatric AIDS and HIV infection. Commun Dis Rep Weekly 1997;7:R132-4.

36 Communicable Disease Surveillance Centre. HIV and AIDS in injecting drug users in the United Kingdom. Commun Dis Rep Weekly 1999;9:317-18.

37 Communicable Disease Surveillance Centre. HIV infection attributed to treatment with clotting factor concentrates (blood products). Commun Dis Rep Weekly 1999;9:353-4.

38 Wadsworth J, Hickman M, Johnson AM, et al. Geographic variation in sexual behaviour in Britain: implications for sexually transmitted disease epidemiology and sexual health promotion. AIDS 1996;10:193-9.

39 European Centre for the Epidemiological Monitoring of AIDS. HIV/AIDS Surveillance in Europe: mid year report, Paris, 2000

40 Michael RT, Wadsworth J, Feinleib J, et al. Private sexual behavior, public opinion, and public health policy related to sexually transmitted diseases: a US-British comparison. Am J Public Health 1998;88:749-54.

41 Nicoll A, Hughes $G$, Donnelly $M$, et al. Assessing the impact of national anti-HIV sexual health campaigns: trends in the transmission of HIV and other sexually transmitted infections in England. Sex Transm Inf 2001;77:242-7.

42 Low N, Daker-White G, Barlow D, et al. Gonorrhoea in inner London: results of a cross sectional study. BM 1997;314:1719-23.

43 Lacey CJN, Merrick DW, Bensley DC, et al. Analysis of the sociodemography of gonorrhoea in Leeds 1989-93. BM 1997;314:1715-18.

44 De Cock KM, Low N. HIV and AIDS, other sexually transmitted diseases, and tuberculosis in ethnic minorities in United Kingdom: is surveillance serving its purpose. BN 1997;314:1747-51 